\title{
White Cord Syndrome: The Terrible Nightmare
}

\author{
Hussein Fathalla ${ }^{*}\left(\mathbb{D}\right.$, Omar Ragab $^{2}$, Ahmed Hamdy Ashry ${ }^{1}$ \\ ${ }^{1}$ Division of Neurosurgery, Cairo University Hospitals, Cairo, Egypt \\ ${ }^{2}$ Division of Neurosurgery, Beni Suef University, Beni Suef, Egypt \\ Email: ^sehs.fathalla@gamil.com
}

How to cite this paper: Fathalla, H., Ragab, O. and Ashry, A.H. (2020) White Cord Syndrome: The Terrible Nightmare. Open Journal of Modern Neurosurgery, 10, 275-283.

https://doi.org/10.4236/ojmn.2020.102030

Received: February 23, 2020

Accepted: April 17, 2020

Published: April 20, 2020

Copyright $\odot 2020$ by author(s) and Scientific Research Publishing Inc. This work is licensed under the Creative Commons Attribution International License (CC BY 4.0).

http://creativecommons.org/licenses/by/4.0/

(c) (i) Open Access

\begin{abstract}
Introduction: Reperfusion injury of spinal cord "white cord syndrome" refers to acute neurological deterioration after decompressive spinal surgery without any reported intraoperative events. The postoperative appearance of diffuse hyperintense intramedullary areas in T2-weighted MRI is characteristic without any other pathological or compressive signs. The etiology may be due to sudden expansion of the cord after reperfusion of chronically ischemic areas leading to disruption of blood-spinal cord barrier. The incidence and risk factors of the syndrome are not well documented in the literature. Methods: This is a retrospective case series that included 150 patients with cervical spondylotic myelopathy who had undergone decompression surgery in our institution from 2017 to 2019. Patients' demographics, clinical, imaging characteristics, intraoperative and postoperative data were collected and analysed. Results: In this study, we documented 7 cases of this syndrome. We found that advanced age, chronic hypertension, pre-existing cord signal in MRI and long history of symptoms may be risk factors for this syndrome. Conclusion: Early diagnosis and prompt treatment of this syndrome with steroids and physical therapy may lead to initial improvement. Awareness of the surgeons about this syndrome should be increased and identifying its risk factors is very important for patients counseling.
\end{abstract}

\section{Keywords}

White Cord Syndrome, Spondylotic, Cervical Myelopathy, Reperfusion Injury

\section{Introduction}

Cervical spondylotic myelopathy (CSM) is a chronic degenerative condition of the cervical spine. It is the most common cause of progressive spinal cord and nerve root malfunction [1]. Traditionally posterior cervical laminectomy with or 
without fusion was recognized as the treatment of choice in cervical spondylotic myelopathy. In spite of being a safe procedure, complications of posterior cervical decompression may reach $14 \%$. C5 palsy, CSF leaks and wound infection are the most common reported complications. Worsening of the neurological status after the procedure is uncommon and may be due to iatrogenic trauma to the cord or epidural hematoma [2].

In very few cases, deterioration of the neurological condition after the surgery may occur without any explanation-the so-called white cord syndrome (WCS). Chin et al. first described it in 2013 following anterior cervical approach [3]. Although the underlying pathophysiology is not entirely clear, ischemic-reperfusion injury remains the most accepted theory. Restoration of blood flow to ischemic areas after acute decompression leads to rapid expansion of the cord and injurious inflammatory cascade [4]. The presence of hyperintense T2 intramedullary signal in the postoperative MRI is characteristic without any residual stenosis or compressive element.

The aim of this study is to increase the awareness of the surgeons and patients about this possible devastating complication. We tried to identify possible risk factors and evaluate the efficacy of treatment strategies mentioned in the literature.

\section{Materials and Methods}

This retrospective study included 150 patient with CSM treated with posterior cervical decompression with or without fusion from December 2017 to July 2019 in Neurosurgery Department at Cairo University Hospitals. Proper history taking and complete neurological examination confirmed diagnosis of cervical myelopathy. All the cases were assessed pre and postoperatively and during the follow up period for 6 months according to Nurick scale (Table 1). MRI cervical spine, CT scans, static and dynamic X rays were done for all patients. All cases with preoperative high T2 signal intensity in MRI were documented. All the cases were treated by cervical laminectomy with or without fusion. The decision to stabilize the cervical spine by using lateral mass screws was taken according to the presence of preoperative cervical instability or reversed cervical spine curvature confirmed by static and dynamic $\mathrm{x}$ rays. Informed consent about the procedure, its possible complications and participation in this study was obtained

Table 1. Nurick scale for grading myelopathy severity.

\begin{tabular}{cc}
\hline Grade & Description \\
\hline 0 & Signs and symptoms of root involvement but no cord disease. \\
1 & Signs of cord disease. Normal gait. \\
3 & Mild gait abnormality. Able to be employed. \\
4 & Gait abnormality prevents employment. \\
5 & Able to walk only with help. \\
\hline
\end{tabular}


from each patient. Two important anesthetic considerations were discussed with anesthesia teams during the procedure. The first one is avoidance of over extension of the neck during intubation. This could be achieved by using fiber-optic laryngoscopy or intubation without any neck movement (manual in-line stabilization or a hard neck collar). The second one is maintenance of spinal cord perfusion by avoiding sudden changes of arterial blood pressure and keeping the patient's mean arterial pressure at $90-105 \mathrm{~mm} \mathrm{Hg}$ throughout the procedure. Stabilization of the neck by the surgeon during positioning of the patient is very important. The surgical procedure was done under general anesthesia in prone position. Cervical laminectomy of the stenotic levels was done meticulously by creating gutters on both sides using high speed drill or $1 \mathrm{~mm}$ kerrison. The procedure was completed by lifting the lamina en bloc and careful dissection between the dura and ligamentum flavum.

We performed an extensive review of the literature to identify the reported cases of WCS. We searched the PUBMED using the keywords "white cord syndrome" and "reperfusion injury" and "spinal cord" and "surgery". We found 7 cases of WCS reported in the literature after surgery of cervical spine pathology: 6 cases of degenerative spine disease and 1 case of cervical tumor (Table 2). Variables like age, coexistence of co morbidities and presence of preoperative MRI hyperintense $\mathrm{T} 2$ signal were observed to identify possible risk factors.

\section{Results}

Among 150 patients with cervical spondylotic myelopathy, we observed 7 cases of WCS (4.6\%). The age of all patients ranged from 40 years to 70 years (mean age is 55 years). These cases experienced postoperative neurological deterioration without any reported events during the procedure. We did postoperative urgent cervical MRI for these patients to exclude epidural hematoma or inadequate

Table 2. Literature review of previously reported cases of WCS after different surgical approaches.

\begin{tabular}{|c|c|c|c|c|c|}
\hline author & $\begin{array}{c}\text { Age/Sex/ } \\
\text { Comorbidity }\end{array}$ & Procedure & $\begin{array}{l}\text { Preop. } \\
\text { signal }\end{array}$ & $\begin{array}{l}\text { Preop. } \\
\text { Nurick }\end{array}$ & $\begin{array}{l}\text { Outcome } \\
\text { Nurick }\end{array}$ \\
\hline Chin et al. 2013 & M59 & Double ACDF, platting & Yes & 3 & 4 \\
\hline $\begin{array}{l}\text { Giammalva } \\
\text { et al. } 2017\end{array}$ & $64 \mathrm{M}$ & $\begin{array}{l}\text { Double ACDF, } \\
\text { interbody cage }\end{array}$ & Yes & 3 & 4 \\
\hline Antwi et al. 2018 & $68 \mathrm{M}$ & $\begin{array}{c}\text { Posterior C4-7 } \\
\text { Lateral mass fixation C3-7 }\end{array}$ & Yes & 1 & 4 \\
\hline $\begin{array}{l}\text { Wiginton JG } \\
\text { et al. } 2019\end{array}$ & $41 \mathrm{M}$ & $\begin{array}{l}\text { Posterior C1 Laminectomy, } \\
\text { superior part of C2 lamina }\end{array}$ & $\begin{array}{c}\text { Not } \\
\text { appeared }\end{array}$ & 1 & N/A \\
\hline $\begin{array}{l}\text { Papaioannou } \\
\text { et al. } 2018\end{array}$ & $\begin{array}{c}\quad 79 \mathrm{M} \\
\text { Hypertension/ } \\
\text { Atrial fibrillation }\end{array}$ & $\begin{array}{l}\text { Posterior C3-C6, lateral } \\
\text { mass fixation C2-7 }\end{array}$ & No & 3 & 4 \\
\hline $\begin{array}{l}\text { Mathkour } \\
\text { et al. } 2020\end{array}$ & $\begin{array}{c}79 \mathrm{M} \\
\text { Hypertension }\end{array}$ & $\begin{array}{c}\text { Posterior C3-5 } \\
\text { Lateral mass C2-6 }\end{array}$ & Yes & 4 & 1 \\
\hline
\end{tabular}


compression. CT cervical spine was done in cases of decompression and fusion to detect any screws malposition. We also did MRI brain to exclude cerebrovascular insufficiency. The hallmark of postoperative images was the presence of enlarged T2 hyperintense signal. No epidural hematoma, cerebral stroke or hardware malposition was detected. All cases of WCS were above 60 years old. 5 cases were males and 2 cases were females. Six cases showed preoperative hyper intense T2 signal in MRI corresponding to the stenotic levels and this abnormal signal showed expansion in the postoperative MRI (Figure 1 and Figure 2). Only one case showed no abnormal intramedullary signal of the spinal cord in the preoperative MRI but a new hyperintense T2 signal appeared in the postoperative MRI. 4 cases underwent cervical laminectomy only and the other 3 cases underwent laminectomy and fusion. All 7 cases were treated with I.V steroids and physiotherapy and no further surgical management was done. All cases of WCS suffered from co-morbidities such as hypertension and 4 cases are also diabetic. Six months after surgery, all the cases showed partial improvement of their neurological status (Table 3).

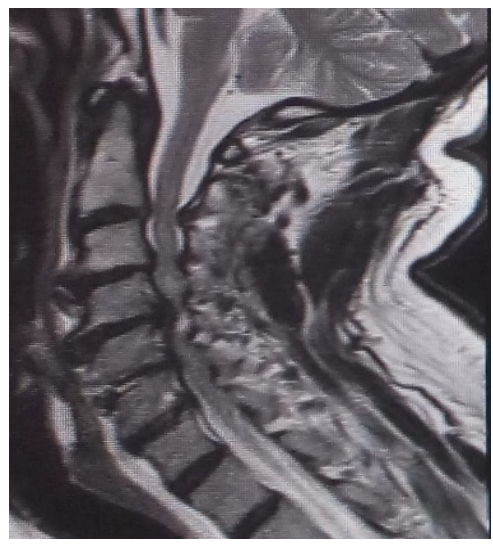

Figure 1. Preoperative MRI cervical spine showing cervical canal stenosis.

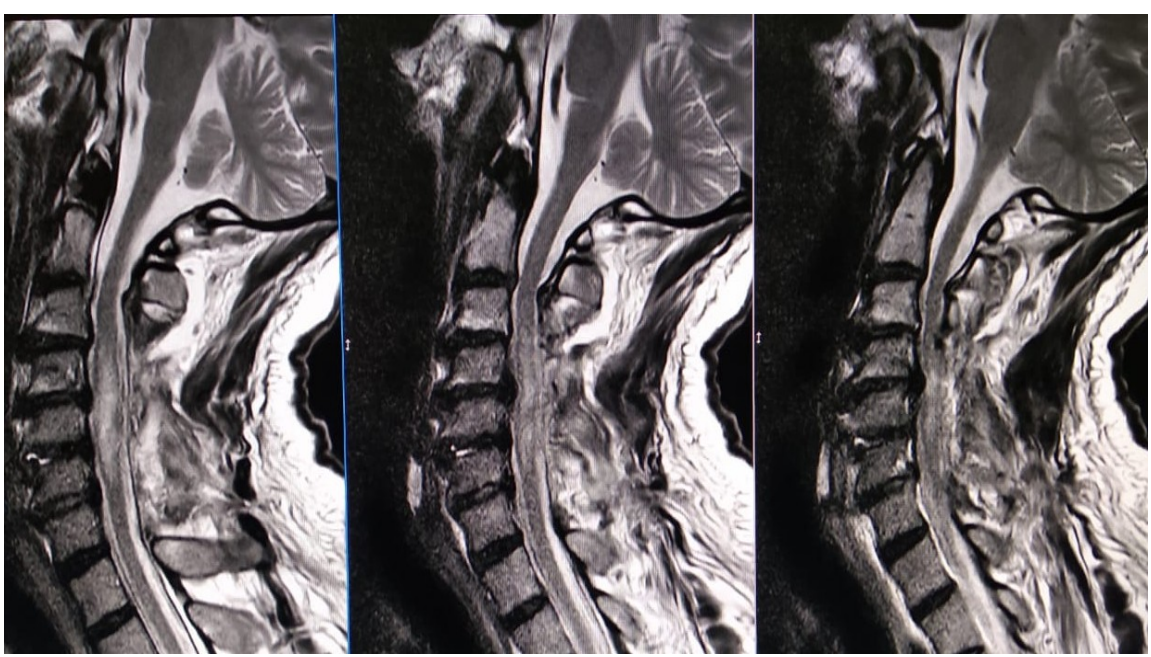

Figure 2. Postoperative MRI cervical spine showing extensive hyperintense T2 signal. 
Table 3. Results of documented cases of WCS in our study.

\begin{tabular}{|c|c|c|c|c|c|}
\hline Case & Age/sex/comorbidity & Procedure & $\begin{array}{l}\text { Preop. MRI } \\
\text { signal }\end{array}$ & $\begin{array}{l}\text { Preop. } \\
\text { Nurick }\end{array}$ & $\begin{array}{l}\text { Outcome } \\
\text { Nurick }\end{array}$ \\
\hline 1 & $\begin{array}{c}62 \mathrm{M} \\
\text { Hypertension/Diabetes }\end{array}$ & $\begin{array}{l}\text { C3-7 laminectomy } \\
\text { and fusion }\end{array}$ & Yes & 2 & 4 \\
\hline 2 & $\begin{array}{c}65 \mathrm{M} \\
\text { Hypertension }\end{array}$ & $\begin{array}{l}\text { C3-6 laminectomy } \\
\text { and fusion }\end{array}$ & Yes & 3 & 4 \\
\hline 3 & $\begin{array}{c}70 \mathrm{M} \\
\text { Hypertension/Diabetes }\end{array}$ & C3-7 laminectomy & Yes & 3 & 4 \\
\hline 4 & $\begin{array}{c}61 \mathrm{M} \\
\text { Hypertension/Diabetes }\end{array}$ & $\begin{array}{l}\text { C3-5 laminectomy } \\
\text { and fusion }\end{array}$ & No & 1 & 3 \\
\hline 5 & $\begin{array}{c}63 \mathrm{M} \\
\text { Hypertension }\end{array}$ & $\begin{array}{l}\text { C3-6 laminectomy } \\
\text { and fusion }\end{array}$ & Yes & 3 & 4 \\
\hline 6 & $\begin{array}{c}69 \mathrm{~F} \\
\text { Hypertension/Diabetes }\end{array}$ & C3-6 laminectomy & Yes & 2 & 4 \\
\hline 7 & $\begin{array}{c}65 \mathrm{~F} \\
\text { Hypertension }\end{array}$ & C3-7 laminectomy & Yes & 2 & 3 \\
\hline
\end{tabular}

\section{Discussion}

Although WCS is a very rare complication, it is a terrible nightmare for both the patients and surgeons. WCS was first described by Chin et al. in 2013 when a 59 years old male with cervical cord compression underwent double level ACDF. The patient developed quadriplegia without any reported intraoperative events [3]. WCS is rarely mentioned in the literature and only few cases were reported as a complication of anterior or posterior decompressive surgery for degenerative spondylotic myelopathy. Two cases of WCS were reported following anterior approach [3] [5], while 4 cases were reported following posterior approach [6] [7] [8] [9]. Only one case of WCS was reported after decompressive surgery and fusion in a case of cervical tumor. Vindoh et al. reported the case of 51 years old paraparetic male affected by $\mathrm{C} 3$ metastatic carcinoma that underwent palliative cervical decompression and fusion. Postoperative the patient developed quadriplegia with difficulty in extubation and treated with high dose intravenous steroids [10].

The pathopysiology of WCS is not entirely clear. Ischemic-reperfusion injury is the most accepted theory to explain this phenomenon and the following several mechanisms are involved [4]:

1) Direct trauma to the cord by the rapid gush of blood following acute decompression.

2) Chronic compression of the cord causes ischemia at the stenotic levels. Decompressive surgery leads to restoration of blood flow to these levels. The free oxygen radical species found in the new blood are responsible for oxidative stress which causes injury of the cord.

3) Another element is lipid peroxidation of the neuronal membranes caused by reactive oxygen species and other inflammatory mediators. 
Risk factors for WCS have not been adequately studied. Advanced age and co-morbidities such as chronic hypertension may increase the risk for WCS. Chronic oxidative stress appears in elderly due to impairment of homeostatic systems such as the immune system. This leads to imbalance between antioxidants and free radical oxygen species with predominance of the latter. This markedly affects all cells of the body including the nervous system [11]. After exclusion of the case of WCS reported in a patient with cervical tumor, the average patient age in other 6 reported cases of WCS was 65 years. Only one of these cases occurred in a patient younger than 50 years. In our study the average patient age was 65 years. All patients in our study were above 60 years. Chronic hypertension causes endothelial damage and atherosclerosis of blood vessels. This leads to disruption of blood-spinal cord barrier increasing its permeability to inflammatory mediators [12]. In previously reported 6 cases, only 2 cases were known to have hypertension. In our study, all 7 cases were known to be hypertensive.

Chronic cervical cord compression may lead to increased T2 signal intensity in preoperative MRI. This abnormality denotes prolonged compression of the cord leading to neuronal loss or myelomalacia and associated with poor outcome. Delayed decompression could exacerbate the reperfusion injury cascade as has been suggested in experimental study in mice [13]. In the previously reported 6 cases, four cases have hyperintense T2 signal area in the preoperative MRI. In our study 6 cases have such an abnormality in the preoperative images corresponding to the stenotic levels. At our institute and due to financial burden, we didn't use intraoperative neurophysiological monitoring in surgery of degenerative spinal disorders. In all cases reported in the literature, electrophysiological monitoring was used. The somatosensory and motor evoked potentials suddenly decreased in voltage during the closure of the superficial planes. Resnick et al. reviewed the literature regarding the use of electrophysiological monitoring during surgery of degenerative spinal disorders. They concluded that it had a little impact on the surgical outcome. It might alarm and result in abortion of the procedure without true neural insult (false positive). It's useful to document the time of the trauma however neural injury could happen without alarming (false negative) [14].

In the absence of any reported intraoperative iatrogenic injury of the cord, other possible factors of worse outcome after surgery should be considered. These factors include epidural hematoma, CSF collection, hardware malposition, residual compression, systemic hypotension and cerebrovascular insufficiency. At our institute we had the ability to perform immediate postoperative MRI and CT scans and keep the operating theatre on standby. MRI cervical spine excluded the presence of residual stenosis, hematoma, and CSF collection. The hallmark of postoperative MRI cervical spine is the expansion of hyperintense T2 signal area. MRI brain excluded any ischemic insult. CT cervical scans confirmed proper position of the screws. The mean arterial pressure was maintained through the procedure at accepted ranges. 
Due to adequate decompression and proper position of the screws confirmed by postoperative images, we didn't need to perform any further decompression. Once the diagnosis of WCS was established, these patients were transferred to rehabilitation unit for intravenous steroids administration and physiotherapy. In the previously reported cases, only 2 cases underwent further surgery. Chin et al. decided to do C5 corpectomy because the postoperative MRI raised their concerns about residual bony compression at C5 [3]. As they didn't have the opportunity to do urgent postoperative MRI in their public hospital, Papaioannou et al. decided to re-explore the wound of their patient who underwent posterior cervical laminectomy and fusion. They didn't find hematoma or CSF collection and they extended the decompression posteriorly to provide space for the cord aiming for possible recovery [7].

Understanding the pathophysiology of WCS helps us plan the treatment strategy. In spinal cord injury, significant improvement of the neurological functions could be achieved if methylprednisolone is administered within 8 hours of injury and continued for 48 hours. Being one of the several mechanisms involved in the pathophysiology of WCS, lipid peroxidation of neurons could be inhibited by steroids [15]. All the reported cases of WCS in the literature were treated with intravenous steroids and witnessed initial improvements in their neurological status. In our study all the patients started steroid therapy immediately ( $8 \mathrm{mg}$ methylprednisolone every 6 hours for 48 hours) and showed some improvement in the consecutive days. As previously mentioned in this section, reactive oxygen species play an important role in the pathophysiology of WCS. Thus potent antioxidants may be effective in the treatment of this syndrome [16].

Due to rarity of this complication and limited number of cases in our study, statistical analysis for the significance of risk factors couldn't be performed. We recommend further studies to confirm the significance of risk factors of WCS such as advanced age, chronic hypertension, preoperative high T2 signal and long standing cervical cord compression. Recognition of this rare phenomenon is very important for patients and surgeons alike. Patients and surgeon should be aware that WCS is a possible cause of devastating paralysis after surgery in the absence of any iatrogenic injury. This is very important for patient counseling and should be included in the preoperative informed consent. Early diagnosis of this complication and exclusion of other causes of unfavorable outcome after cervical decompressive surgery is very crucial. Proper understanding of the pathophysiology of WCS helps planning of future treatment strategies. We believe that absence of intraoperative neurophysiological monitoring which is helpful in documenting the time of injury is one of the limitations of this study. Also we recommend measurement of serum level of inflammatory markers in cases of WCS to confirm the pathogenesis of this syndrome.

\section{Conclusion}

White cord syndrome is a rare complication but it usually leads to catastrophic 
outcomes. Diagnosis of WCS is usually done by exclusion. Deterioration of the motor power of the patients in absence of intraoperative iatrogenic injury of the cord and systemic hypotension should raise the suspicious of the surgeons about this syndrome. The characteristic abnormality in the postoperative MRI is the expansion of hyperintense T2 signal. This study included the largest number of patients of this syndrome. Advanced age, co-morbidities such as chronic hypertension and long standing cervical compression should be identified as risk factors. Steroids and physiotherapy remain the cornerstone of management of WCS.

\section{Conflicts of Interest}

The authors declare no conflicts of interest regarding the publication of this paper.

\section{References}

[1] Benzel, E.C. (2005) Spine Surgery: Techniques, Complication Avoidance, and Management. Churchill Livingstone, London.

[2] Fehlings, M.G., Tetreault, L., Hsieh, P.C., Traynelis, V. and Wang, M.Y. (2016) Introduction: Degenerative Cervical Myelopathy: Diagnostic, Assessment, and Management Strategies, Surgical Complications, and Outcome Prediction. Neurosurgical FOCUS, 40, E1. https://doi.org/10.3171/2016.3.FOCUS16111

[3] Chin, K.R., Seale, J. and Cumming, V. (2013) "White Cord Syndrome" of Acute Tetraplegia after Anterior Cervical Decompression and Fusion for Chronic Spinal Cord Compression: A Case Report. Case Reports in Orthopedics, 2013, Article ID: 697918. https://doi.org/10.1155/2013/697918

[4] Chen, H., et al. (2011) Oxidative Stress in Ischemic Brain Damage: Mechanism of Cell Death and Potential Molecular Targets for Neuroprotection. Antioxidants \& Redox Signaling, 14, 1505-1517. https://doi.org/10.1089/ars.2010.3576

[5] Giammalva, G.R., Maugeri, R., Graziano, F., Gulì, C., Giugno, A., Basile, L. and Iacopino, D.G. (2017) White Cord Syndrome after Non-Contiguous Double-Level Anterior Cervical Decompression and Fusion (ACDF): A "No Reflow Phenomenon"? Interdisciplinary Neurosurgery, 7, 47-49. https://doi.org/10.1016/j.inat.2016.12.001

[6] Antwi, P., Grant, R., Kuzmik, G. and Abbed, K. (2018) "White Cord Syndrome" of Acute Hemiparesis after Posterior Cervical Decompression and Fusion for Chronic Cervical Stenosis. World Neurosurgery, 113, 33-36. https://doi.org/10.1016/j.wneu.2018.02.026

[7] Papaioannou, I., Repantis, T., Baikousis, A. and Korovessis, P. (2019) Late-Onset "White Cord Syndrome" in an Elderly Patient after Posterior Cervical Decompression and Fusion: A Case Report. Spinal Cord Series and Cases, 5, 28. https://doi.org/10.1038/s41394-019-0174-Z

[8] Wiginton, I.V., Brazdzionis, J., Mohrdar, C., Sweiss, R. and Lawandy, S. (2019) Spinal Cord Reperfusion Injury: Case Report, Review of the Literature, and Future Treatment Strategies. Cureus, 11, e5279. https://doi.org/10.7759/cureus.5279

[9] Mathkour, M., Werner, C., Riffle, J., Scullen, T., Dallapiaza, R.F., Dumont, A. and Maulucci, C. (2020) Reperfusion "White Cord" Syndrome in Cervical Spondylotic Myelopathy: Does Mean Arterial Pressure Goal Make a Difference? Additional Case 
and Literature Review. World Neurosurgery, pii: S1878-8750(20)30070-X.

[10] Vinodh, V.P., Rajapathy, S.K., Sellamuthu, P. and Kandasamy, R. (2018) White Cord Syndrome: A Devastating Complication of Spinal Decompression Surgery. Surgical Neurology International, 9, 136. https://doi.org/10.4103/sni.sni_96_18

[11] Fuente, M. and Miquel, J. (2009) An Update of the Oxidation-Inflammation Theory of Aging: The Involvement of the Immune System in Oxiinflamm-Aging. Current Pharmaceutical Design, 15, 3003-3026. https://doi.org/10.2174/138161209789058110

[12] Strolin Benedetti, M., Dostert, P., Marrari, P. and Cini, M. (1993) Effect of Ageing on Tissue Levels of Amino Acids Involved in the Nitric Oxide Pathway in Rat Brain. Journal of Neural Transmission. General Section, 94, 21-23. https://doi.org/10.1007/BF01244980

[13] Vidal, P.M., Karadimas, S.K., Ulndreaj, A., Laliberte, A.M., Tetreault, L., Forner, S., et al. (2017) Delayed Decompression Exacerbates Ischemia Reperfusion Injury in Cervical Compressive Myelopathy. JCI Insight, 2, e92512. https://doi.org/10.1172/jci.insight.92512

[14] Resnick, D.K., Anderson, P.A., Kaiser, M.G., Groff, M.W., Heary, R.F., Holly, L.T., et al. (2009) Electrophysiological Monitoring during Surgery for Cervical Degenerative Myelopathy and Radiculopathy. Journal of Neurosurgery Spine, 11, 245-252. https://doi.org/10.3171/2009.2.SPINE08730

[15] Bracken, M.B. (2012) Steroids for Acute Spinal Cord Injury. Cochrane Database of Systematic Reviews, 18, CD001046. https://doi.org/10.1002/14651858.CD001046.pub2

[16] Shirley, R., Ord, E.N.J. and Work, L.M. (2014) Oxidative Stress and the Use of Antioxidants in Stroke. Antioxidants (Basel), 3, 472-450. https://doi.org/10.3390/antiox3030472 